5. Ferrone R, Scarone PC, Natalini G. Late complication of open inguinal hernia repair: Small bowel obstruction caused by intraperitoneal mesh migration. Hernia. 2003;7:161-2.

6. Losanoff JE, Richman BW, Jones JW. Entero-colocutaneous fistula: a late consequence of polypropylene mesh abdominal wall repair: case report and review of the literature. Hernia. 2002;6:144-7.

7. Lange B, Langer C, Markus PM, Becker H. Mesh penetration of the sigmoid colon following transabdominal preperitoneal hernia repair. Surg Endosc. 2003;17:157.

8. El Hakam MZ, Sharara AI, Chedid V. Persistent left lower abdominal pain: Mesh migration into the sigmoid Colon. Gastroenterol. 2010;138:e5-6

9. Ott V, Groebli Y, Schneider R. Late intestinal fistula formation after incisional hernia using intraperitoneal mesh. Hernia. 2005;9:103-04.

10. de Hoyos A, Villegas O, Sanchez JM, Monroy M A. Endoloops as a therapeutic option in colocutaneous fistula closure. Endoscopy. 2005;37:1258.

11. Parra JA, Revuelta S, Gallego T, Bueno J, Berrio JI, Farinas MC. Prosthetic mesh used for inguinal and ventral hernia repair: Normal appearance and complications in ultrasound and CT. Br J of Radiol. 2004;77:261-5.

\section{Filiform ulcerative colitis-rare entity captured}

Filiform polyposis is an uncommon entity that is most often encountered in the colon of patients with a history of IBD. It is characterized by a large number of worm-like polyps lined by histologically normal colonic mucosa. They usually have a thin, straight shape resembling the stalks of polyps without the heads, range in size from $1.5-3.0 \mathrm{~cm}$ in length and $0.5 \mathrm{~cm}$ in diameter and can occur as solitary polyps or as diffuse polyposis distributed over large areas of the colonic mucosa. Long-term inflammation of the colonic mucosa during chronic IBD with alternating periods of ulceration and healing may lead to the formation of finger-like projections, so-called filiform polyps. Several filiform polyps form large tumor masses, termed giant filiform polyposis. Histologically, the polyps are filiform, with a central core, containing vessels and smooth muscle fibers. Clinicopathologic and immunophenotypic studies regarding filiform polyposis without IBD demonstrate that there is generalized polyposis, considered to be an asymptomatic sequela of ulcerative colitis. Filiform polyposis may resemble villous adenomas on colonoscopy, biopsy should be recommended in all cases. Filiform polyposis alone is not an indication for surgical resection, but complications, such as acute massive hemorrhage or intestinal obstruction, may necessitate surgical intervention.The pathologic specimen of right hemicolectomy shows filiform polyposis in the ascending colon and transverse colon with satellite lesions in a known case of ulcerative colitis.

\section{SATPAL SINGH VIRK ${ }^{1}$ GARIMA DAGA DR VARUN MITTAL $L^{2}$}

Correspondence: Dr. Satpal Singh Virk MCH Surgical Gastroenterology ${ }^{1}$ and MS Surgery Dayanand Medical College and Hospital,

Ludhiana, India

Email:satpalsinghvirk@yahoo.com

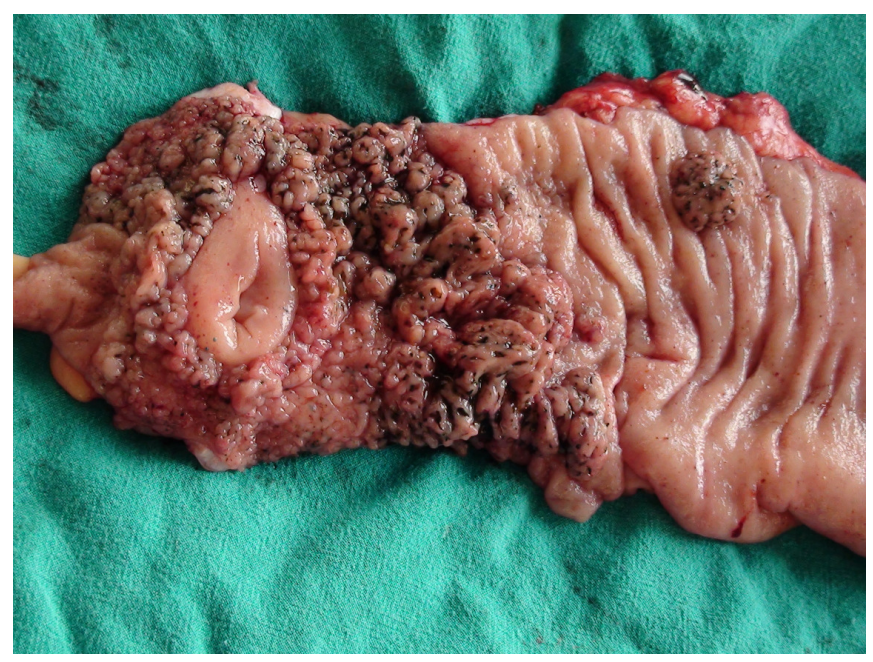

